OPEN ACCESS

Edited by:

Amalia Gastaldelli,

National Research Council (CNR), Italy

Reviewed by:

Maria Paula Macedo,

New University of Lisbon, Portugal

Devjit Tripathy,

The University of Texas Health Science Center at San Antonio, United States

*Correspondence: Pirjo Nuutila pirjo.nuutila@utu.fi

Specialty section: This article was submitted to Diabetes: Molecular Mechanisms, a section of the journal

Frontiers in Endocrinology

Received: 07 July 2021 Accepted: 15 September 2021 Published: 04 October 2021

Citation:

Laurila S, Rebelos E, Honka M-J and Nuutila P (2021) Pleiotropic

Effects of Secretin: A Potential Drug Candidate in the Treatment of Obesity?

Front. Endocrinol. 12:737686. doi: 10.3389/fendo.2021.737686

\section{Pleiotropic Effects of Secretin: A Potential Drug Candidate in the Treatment of Obesity?}

\author{
Sanna Laurila ${ }^{1,2,3}$, Eleni Rebelos ${ }^{1}$, Miikka-Juhani Honka ${ }^{1}$ and Pirjo Nuutila ${ }^{1,4 *}$ \\ 1 Turku PET Centre, University of Turku, Turku, Finland, ${ }^{2}$ Heart Center, Turku University Hospital, Turku, Finland, \\ ${ }^{3}$ Department of Cardiology, Satakunta Central Hospital, Pori, Finland, ${ }^{4}$ Department of Endocrinology, Turku University \\ Hospital, Turku, Finland
}

Secretin is the first hormone that has been discovered, inaugurating the era and the field of endocrinology. Despite the initial focus, the interest in its actions faded away over the decades. However, there is mounting evidence regarding the pleiotropic beneficial effects of secretin on whole-body homeostasis. In this review, we discuss the evidence from preclinical and clinical studies based on which secretin may have a role in the treatment of obesity.

Keywords: secretin, obesity, gastric hormone, brown adipocyte, appetite

\section{INTRODUCTION}

We are currently facing a global epidemic of obesity (1). Obesity poses an additional risk for several diseases comprising cancer, neurodegeneration, cardiovascular disease (CVD), musculoskeletal disorders, and an increased vulnerability to infections (2-6). Of these CVD is the leading cause of death world-wide (7). While lifestyle modification has been shown to be only a weak arm in the battle against obesity, bariatric surgery (BS) represents today the most effective treatment to induce significant and sustained weight loss. As recently demonstrated by Yoshino et al., the beneficial metabolic effects of BS can be ascribed solely to weight loss itself, rather than to any weight-lossindependent effects (8).

It is now well-established that the beneficial effects of BS on weight loss are not only to be attributed to decreased nutrient intake, and decreased nutrient absorption, but several other mechanisms are involved, such as the marked elevation of gut-derived peptides with anorexigenic action, such as glucagon-like peptide 1 (GLP-1). GLP-1 is secreted by the L cells of the intestine in response to feeding. Apart from being an incretin hormone (thus stimulating insulin secretion after oral ingestion of nutrients), GLP-1 has important effects on regulating appetite.

Abbreviations: BAT, brown adipose tissue; BS, bariatric surgery; CNS, central nervous system; CSS, composite satiety score; CVD, cardiovascular disease; FFA, free fatty acids; fMRI, functional magnetic resonance imaging; GI, gastrointestinal; GLP-1, glucagon-like peptide 1; PET, positron emission tomography; TRPV1, Transient receptor potential vanilloid; UCP1, uncoupling protein 1; VAS, visual analogue scale. 
Semaglutide, a long-acting GLP-1 analogue, has recently shown promising results in terms of weight loss, with subjects receiving $2.4 \mathrm{mg}$ of Semaglutide once weekly on top of lifestyle intervention (9).

The intestines secrete several other hormones as well. One such is secretin, which has recently gained back interest from the metabolic community. It was discovered in 1902 by Bayliss and Starling to stimulate pancreatic fluid secretion, becoming the first hormone ever discovered and inaugurating the era and the field of endocrinology. Since then it has been shown that secretin receptors are present in nearly every organ throughout the body (10). Aside from the classic exocrine effects, secretin has several interesting metabolic effects. It is a powerful lipolytic agent and its levels are increased after prolonged fasting (11). Moreover, preclinical and clinical studies have recently shown that secretin may induce satiation $(12,13)$. Also following bariatric surgery, secretin levels have shown to be increased (14). Taken together the gastrointestinal hormone secretin may have potential in future weight loss strategies. In this review, we describe the basic characteristics of secretin secretion and its effects on wholebody homeostasis, with special interest in its action as a satiation signal.

\section{REGULATION OF SECRETIN SECRETION AND GASTROINTESTINAL EFFECTS}

Human secretin is synthesized as a pre-propeptide of 121 amino acid residues, containing a signal peptide (residues 1-18), propeptide (19-26), secretin (28-54), and propeptide (58-121) (15). This pre-propeptide is cleaved from both ends to achieve the active peptide of 27 amino acid residues. Secretin is predominantly synthesized by the S-cells in the crypts of Lieberkühn of the duodenal epithelium (16). Other sites with relatively high expression of secretin mRNA include intestinal enteroendocrine cells in the jejunum, ileum, colon, and rectum as well as plasmacytoid dendritic cells (17). Its release is initiated during feeding, when acidic contents of the stomach move into

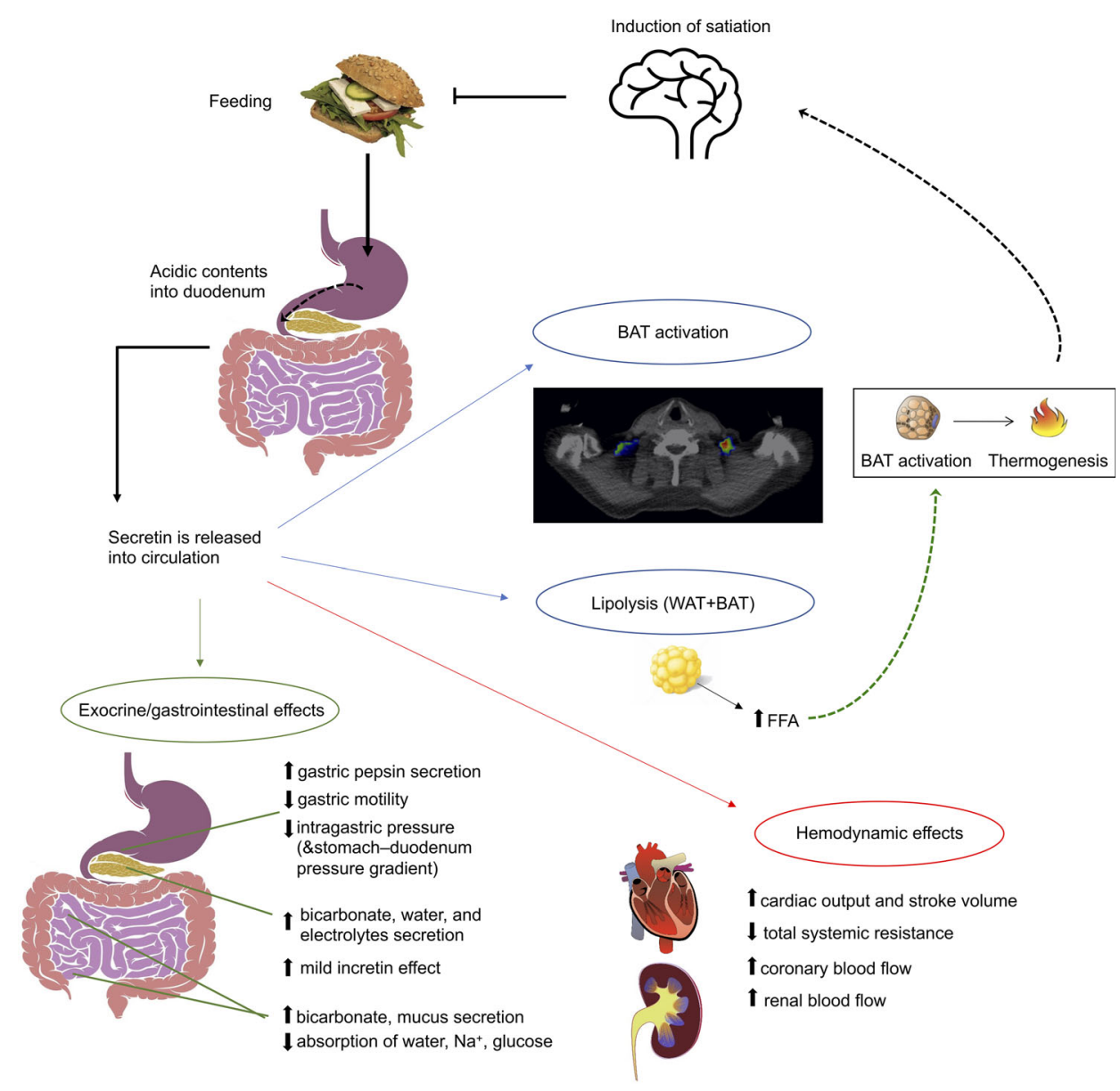

FIGURE 1 | Figure summarizing the best-established effects of secretin. Apart from the well-established exocrine functions of secretin, it also has a mild incretin effect, induces appetite and brown adipose tissue (BAT) activation. Also, during prolonged fasting it enhances lipolysis. Secretin has also been shown to increase cardiac output and stroke volume. 
the duodenum (16) and duodenal $\mathrm{pH}$ decreases to 3 - 4.5 (18, 19) (Figure 1).

In rats, Green and colleagues showed that secretin secretion is larger after intraduodenal infusion of fat, compared to protein (20).Also, the fatty-acid composition of a meal induces different levels of secretin release. In a study comparing equicaloric fat emulsions, given intraduodenally in women who had undergone cholecystectomy, it was shown that whereas neutral fat did not induce any significant secretin release compared to the fasting state, medium-chain fatty acids yielded a large increase in secretin release (21). Notably, the consumption of the medium-chain fatty acid meal was followed also by a marked decrease in intraduodenal $\mathrm{pH}$, whereas neutral fat modified the $\mathrm{pH}$ values only slightly. However, no significant differences were found in the intraduodenal $\mathrm{pH}$ values between the 2 groups at postprandial states. Thus, the authors proposed that even though the duodenal acidity is an important determinant of secretin release, other factors are also involved which may potentiate the secretin response, and even alter the $\mathrm{pH}$ threshold of secretin secretion (21). Recently, glucose was also shown to promote secretin's release (14), even though to the best of our knowledge a direct comparison between glucose and FFA stimulation of secretin release has not been investigated. All in all, the exact mechanisms controlling secretin's release are incompletely understood. A secretin-releasing peptide has been found to promote it, but the exact nature of this mechanism is unclear $(22,23)$. Pancreatic phospholipase A2 from the upper small intestine has also been found to stimulate secretin release $(24,25)$.

The oldest and best-known function of secretin is the stimulation of pancreatic exocrine secretion (10). This is also initiated by vasoactive intestinal peptide (VIP), cholecystokinin (CCK) and vagal stimulation (10). Secretin also neutralizes the acidic contents of the duodenal lumen by stimulating pancreatic acinar cells and duodenal Brunner's glands to produce bicarbonate and water $(26,27)$, and by inhibiting gastric acid secretion and gastric motility (10). The intestinal lining is protected by these effects, while digestive enzymes start to break down nutrients (10). In addition to ingested nutrients, pancreatic proteases also break the secretin releasing peptide, creating a negative feedback loop for secretin release (23). Secretin also induces biliary secretion of water, bicarbonate and chloride (28), but not bile acids (29), while inhibiting the absorption of water, sodium, and glucose in the jejunum and ileum (30-33).

\section{PHARMACOKINETICS}

Secretin has a relatively short half-life in plasma in humans (2.5$4.0 \mathrm{~min}$ ) (34-37). Animal studies have revealed that secretin removal from the circulation occurs mainly through the kidneys (38) but also the capillary beds of various other tissues $(39,40)$. Despite the kidneys being an important organ for secretin removal, only small amounts of secretin appear in the urine
(41) because, after glomerular filtration, secretin is reabsorbed in the distal part of the nephron $(42,43)$. Further research is required to understand the pharmacokinetics of secretin in humans and its molecular mechanisms.

\section{CURRENT CLINICAL USES}

Currently, synthetic secretin is in clinical use solely for rare and specific diagnostic purposes. In Zollinger-Ellison syndrome, a rare neuroendocrine tumour (gastrinoma) produces high levels of gastrin (44), leading to abnormally increased gastric acid production. A secretin stimulation test can be performed, if a gastrinoma is suspected but gastric $\mathrm{pH}$ and serum gastrin levels are not diagnostic. After an overnight fast, a bolus of secretin is given $(2 \mathrm{IU} / \mathrm{kg})$ intravenously, and serum gastrin levels are measured at $0,2,5,10$ and 15 minutes. Even though in normal subjects, secretin inhibits gastrin release (45), it stimulates the gastrinoma cells to release gastrin, which leads to a significant increase in serum gastrin levels. Serum gastrin levels greater than $200 \mathrm{pg} / \mathrm{ml}$ are diagnostic. Secretin is sometimes also used to investigate exocrine pancreatic insufficiency $(46,47)$. It can be given during magnetic resonance cholangiopancreatography, in order to study pancreatic exocrine function, or to evaluate the anatomy of the pancreatic duct (48).

\section{HEMODYNAMIC EFFECTS OF SECRETIN}

Early studies have shown that pharmacological doses of secretin increase renal blood flow in healthy humans by 58\% (49), and subsequently in patients with angina and heart failure (NYHA class III-IV) it was shown that a secretin infusion significantly increases cardiac output $(20 \%)$ and stroke volume $(50,51)$. Systemic resistance was decreased, while heart rate was not affected. These effects are indicative of a vasodilator effect of secretin, whereas an inotropic effect of secretin is also likely (50). Our group is currently investigating whether secretin has effects on myocardial metabolism and renal function on healthy humans, assessed with $\left[{ }^{18} \mathrm{~F}\right]-\mathrm{FDG}-\mathrm{PET}$ (NCT03290846).

\section{EFFECTS OF SECRETIN IN THE LUNGS}

In addition to the gastrointestinal tract, the secretin receptor is abundantly expressed in the distal regions of the lungs (52), specifically in type 2 alveolar cells (17) that are responsible for surfactant secretion (53). In addition, some secretin receptor expression is present in the club cells of the bronchiolar epithelium (17), and tertiary bronchial smooth muscle (52). It is likely that secretin participates in maintaining the airway surface liquid and mucociliary clearance, and bronchial smooth muscle relaxation (52). 


\section{SECRETIN AS A NEUROPEPTIDE}

The potential central effects of secretin were first recognized when secretin-like bioactivity was found in porcine brain extracts (54). A study on human brains found secretin immunoreactivity in the pyramidal neurons of the motor cortex, deep cerebellar nuclei, cerebellar Purkinje cells and the hippocampal and amygdala nuclei (55). Spatially, the secretin receptor is even more widely distributed than its ligand, which may indicate that several different neuronal functions could be modulated by secretin (56). Secretin may even be important in early postnatal neurological development. In secretin deficient mice, hippocampal neurogenesis was disturbed, which lead to impaired neurobehavioral development (57). Secretin deficiency also led to impaired synaptic plasticity in the hippocampus (58).

Secretin could also have wide effects on the autonomic nervous system, since it has been shown to have regulatory effects on catecholamine metabolism in the axon terminals of sympathetic nerves (59). It also has a stimulatory effect on cyclic adenosine monophosphate (cAMP) production (60). cAMP regulates the enzyme tyrosine hydroxylase (61), which catalyses the rate limiting step of catecholamine biosynthesis. Secretin has been shown to increase tyrosine hydroxylase activity in the sympathetic ganglia and several autonomic end organs (62). When rats were given an interventricular infusion of secretin, there was an increase in tyrosine hydroxylase activity in the hypothalamus (63).

Rodent studies indicate that secretin is also involved in the regulation of dihydroxyphenylalanine (DOPA) synthesis and turnover (64). Secretin also facilitates gamma-aminobutyric acid, or GABAergic input of Purkinje cells in the cerebellum $(65,66)$ and vasopressin expression and release in the hypothalamus (64). However, this effect on both vasopressin and oxytocin release may also be through a noradrenergic pathway, as shown in a rat model by Velmurugan et al. (67). All in all, it has been proposed, that the central actions of secretin may be related to fluid homeostasis $(68,69)$, food intake $(70)$ and control of social behaviour $(71,72)$. These effects by peripherally secreted secretin would be mediated through the autonomic nervous system (ANS) $(70,73)$, or directly after transmembrane diffusion of the hormone (74).

\section{FLUID HOMEOSTASIS}

Initially it seemed that secretin had a diuretic effect on dogs and humans (75), but there were opposite findings in rats (76). Secretin increases renal blood flow (77), and glomerular filtration rate and glomerular plasma flow are also increased in dogs (78). More recent studies in mice showed that secretin stimulates vasopressin expression and release in the hypothalamus (68), and also increases renal water absorption through a vasopressin-independent mechanism on aquaporin 2 channels in the collecting tubules in hyperosmolar conditions (79). Centrally injected secretin induced water drinking behaviour in rats, which increased diuresis, while peripherally injected secretin did not have this effect (69). Thus, it is likely that secretin's effect on fluid homeostasis varies depending on whether its effect is peripheral or central, or depending on conditions such as osmolarity or serum secretin concentration.

\section{APPETITE CONTROL}

Another suggested central effect of secretin is appetite control (73). In an elegant study, Yang and colleagues demonstrated that an intraperitoneal injection of secretin induces a dose-dependent increase in the number of Fos-positive neurons in the arcuate nucleus, the hypothalamic nucleus that suppresses appetite (73). Subsequently it was shown that both peripheral and central administration of secretin suppresses appetite in mice (80), and that following either vagotomy, or administration of capsaicin, an afferent neurotoxic agent, the anorexigenic effects of secretin were attenuated (70).

\section{INSULIN SECRETION AND GLUCOSE HOMEOSTASIS}

Secretin has a mild incretin effect, but this effect is much smaller than that of GLP-1 and GIP. Early studies showed that insulin secretion was increased by secretin during a glucose infusion and pre-treating patients with secretin also potentiated glucosestimulated insulin release (81). The increase in insulin levels was small and only lasted a few minutes, due to which the authors suggested that secretin only stimulates the first phase of insulin release and not production (82).

In another study on healthy subjects, a physiological dose of intravenous secretin $(0.5 \mathrm{pmol} / \mathrm{kg})$ did not induce an increase in insulin secretion, whereas pharmacologic doses of secretin (16 $\mathrm{pmol} / \mathrm{kg}$ ) induced a significant increase in plasma insulin concentrations, which returned to pre-stimulus values after 20 minutes (83). Isoprotenerol and secretin-induced insulin release was blunted in the same effect in adult-onset diabetics, compared to healthy controls (84).

\section{SECRETIN AND LIPOLYSIS}

Secretin receptors induce lipolysis in white adipose tissue, initiated by its ligand $(85,86)$. This happens through Gscoupled cAMP - protein kinase A (PKA) signalling, independently of sympathetic activation (87). During prolonged fasting, plasma secretin levels are increased almost 8 -fold from day 1 to $3(11,88-90)$. These levels are much higher than the levels achieved through feeding and supports secretin's role as a potent lipolytic agent $(85,86)$. The mechanism by which the increased secretin levels are achieved is not known but it is independent of hydrochloric acid concentration $(88,91)$. Secretin levels have also been studied during exercise when lipolysis is also increased. A 3 hour bicycle exercise 
intervention markedly increased serum secretin levels, both during exercise and after 3 hours of rest (92). O'Connor et al. investigated marathon runners and found that secretin levels were increased along with all other examined gastrointestinal peptides, except for insulin both immediately and 30 minutes after finishing the race (93). At the time, no direct speculation was made on the mechanism or purpose. It was previously unknown what effect secretin has on brown adipose tissue (BAT). Since lipolysis is important not only in fuelling, but also initiating uncoupling protein 1 (UCP1) thermogenesis in BAT, studies on secretin as a BAT activator seemed warranted.

\section{SECRETIN AND OBESITY}

There is evidence that the increase of serum secretin in prolonged fasting is blunted in obesity. In a study conducted by Andrews et al., gastric hormone levels were measured after 12 and 36 hours of fasting and after an oral glucose tolerance test (OGTT) (94). Secretin, glucagon, and vasoactive intestinal polypeptide (VIP) increased in lean but not obese after $36 \mathrm{~h}$ of fasting (94). Further, obese subjects had an insulin secretion response to a smaller dose of secretin than lean ones, even if the response to a higher dose was similar in groups (94). Potential differences in fasting and postprandial secretin levels in lean and obese subjects have not been thoroughly investigated, but a small study by Vezina et al. reported no difference in the fasting and postprandial secretin levels after ingestion of a small volume liquid fatty meal to promote gallbladder emptying, between lean and obese subjects (95).

Expression of the secretin receptor may also be affected by obesity, as a positive correlation between BMI and ApoB levels with the SCT receptor expression in omental fat in humans has been described (96).

\section{SECRETIN AND BARIATRIC SURGERY}

In a study by Miskowiak et al. in 1984, 11 morbidly obese patients underwent gastroplasty and plasma secretin levels were measured before and 3 months after (97). Postprandial secretin levels were higher after gastroplasty compared to before the operation, but the difference was not statistically significant, which could be either due to the small sample size $(n=11)$ or the operation technique (97). Interestingly, a recent study by Modvig et al. noted a two- to threefold increase in postprandial secretin three months after RYGB (14). Nergård et al. also noted a two- to threefold increase in postprandial secretin three months after RYGB (98).

The increase in postprandial secretin levels is in line with a finding in rats that underwent RYGB, where secretin was found to be upregulated after the operation in the alimentary limb and proximal common channel (99). Modvig et al. showed with a rat model, that there are glucose sensitive S-cells in the distal part of the small intestine, which could explain the increase in postprandial secretin after RYGB (14). In humans, the results are somewhat conflicting. Nergård et al. found no increase of secretin secreting cells in the perianastomotic jejunum in 18 patients 12 months after RYGB (98). In a study by Rhee et al, mucosal biopsies were collected from the small intestine during surgery and 10 months after RYGB (100). Immunohistochemistry and RNA sequencing results from different biopsy sites were compared in 12 patients with T2D and 11 healthy subjects. Secretin encoding SCT was reduced significantly in all biopsy sites (alimentary limb, secretory limb and common limb), except the alimentary limb of the non-diabetic group (100). Taken together, even though most clinical studies suggest an increase in circulating secretin levels following bariatric surgery, the results regarding the expression of the secretin receptor are conflicting. Therefore, more studies are needed in order to clarify this and also to address whether some of the beneficial effects following bariatric surgery may be attributed to changes in secretin levels.

\section{SECRETIN: A NOVEL MEDIATOR OF AN APPETITE CONTROLLING GUT-BAT- BRAIN AXIS}

It was recently shown with in vitro and in vivo experiments, that secretin has a thermogenic effect on BAT (12) (Figure 2). Secretin activated thermogenesis in a culture of adherent primary brown adipocytes, an effect which was much stronger ( $~ 50$-fold) than that of isoproterenol, a $\beta$-adrenergic receptor agonist (12). The thermogenic effect of secretin was independent of activation of the adrenergic receptors, since pre-treatment of brown adipocytes with propranolol did not affect secretin-stimulated respiration, while blocking isoproterenol-stimulated respiration (12). Secretin stimulation resulted in a dose-dependent increase of cytosolic cAMP (12). Next, the thermogenic effect of secretin was also confirmed in vivo in mice with the utilization of indirect calorimetry and multispectral optoacoustic tomography. The former measures gas exchanges, whereas the latter detects the spectra of oxygenated and deoxygenated haemoglobin. It was shown that relative oxygen saturation was markedly decreased following secretin administration (12).

While it had already been shown that peripheral and central administration of secretin reduces food intake in fasted mice (80), the exact mechanism for this effect was not elucidated. To explore whether the satiety-inducing effect of secretin was through BAT activation, UCP1 wild type and knockout $(\mathrm{KO})$ mice were studied. UCP1 KO mice did not reduce their food intake following secretin administration, confirming that this effect of secretin is mediated through BAT activation (12). However, this effect is limited to only an initial phase of feeding, possibly because of the short half-life of the peptide. Furthermore, when endogenous secretin was neutralized by an antibody, meal size and duration was significantly increased compared to controls (12). These results confirmed that the satiation effect is induced by secretin and BAT thermogenesis (Figure 2). The neurobiological basis of the effect was then studied with hypothalamic samples, collected from fasted WT and UCP1 KO mice after intraperitoneal injections of secretin. Secretin increased proopiomelanocortin (POMC) and decreased agouti-related protein (AgRP) mRNA levels in WT mice (12). 


\section{Secretin's potential as an antiobesity agent}

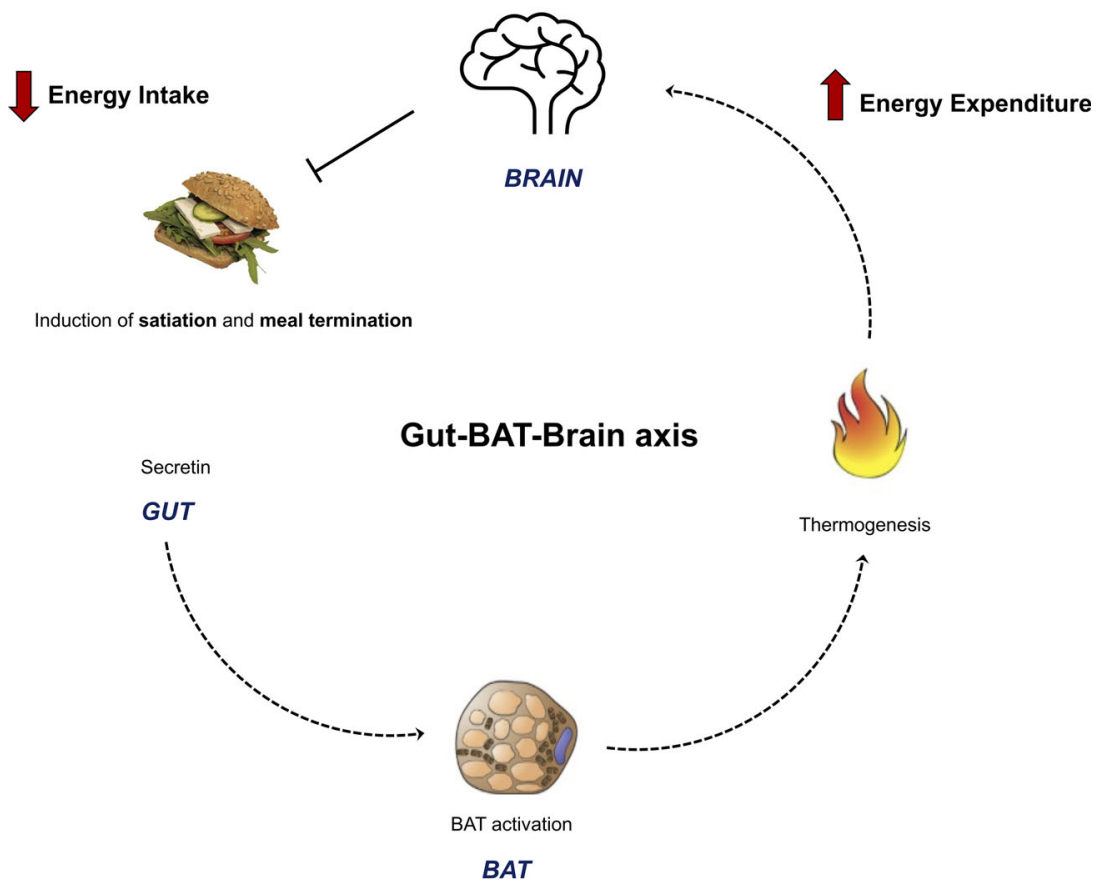

FIGURE 2 | Figure summarizing the novel anti-obesity effects of secretin. Li et al., 2018 showed the presence of a gut - BAT - brain -axis with rodent models. Secretin, secreted by the gut during feeding, binds to secretin receptors in brown adipose cells. This induces thermogenesis, which functions as a satiation signal for the brain and terminates feeding. Secretin's BAT activation and satiation effects were shown to translate to humans by Laurila et al., 2021 . These results highlight that secretin has a rare dual role on energy homeostasis, potentially both increasing energy expenditure and decreasing energy intake. This makes it an attractive anti-obesity agent for further studies.

POMC neurons have anorexigenic effects, while AgRP have orexigenic effects. Furthermore, temperature sensitive ion channels; transient receptor potential vallinoid 1 (TRPV1) were upregulated in the POMC neurons of WT mice, supporting the hypothesis of heat, generated by BAT, functioning as an appetite reducing message to the central nervous system (12).

\section{RECENT PET AND fMRI DATA}

We have recently conducted an imaging study that further highlights the potential of secretin as an anti-obesity agent in humans (Figure 2). Positron emission tomography (PET) represents the state-of-the art method for quantifying metabolic rates in vivo in humans. Based on the tracer used, different metabolic aspects can be evaluated $(101-104)$. $\left[{ }^{18} \mathrm{~F}\right]-\mathrm{FDG}-\mathrm{PET}$ is considered the gold standard method for studying BAT activation in humans (105), while perfusion by $\left[{ }^{15} \mathrm{O}\right]-\mathrm{H}_{2} \mathrm{O}$-PET is considered an indirect measure of BAT thermogenesis, because it has been shown to associate with BAT oxygen consumption (106).

We have recently conducted a study where secretin's effects were investigated with whole body $\left[{ }^{18} \mathrm{~F}\right]$-FDG-PET, to measure glucose uptake rates, and $\left[{ }^{15} \mathrm{O}\right]-\mathrm{H}_{2} \mathrm{O}-\mathrm{PET}$, to measure BAT perfusion. In accordance with our previous findings in mice, we showed that secretin activates BAT in healthy lean men (13). More specifically, secretin induced an increase in $\left[{ }^{18} \mathrm{~F}\right]-\mathrm{FDG}$ uptake in BAT, suggestive of increased metabolic activity, while perfusion was not changed in an acute setting (13). In mice, maximal thermogenesis was achieved 20 minutes after secretin administration (12). The $\left[{ }^{18} \mathrm{~F}\right]-$ FDG scan was initiated 20 minutes after the first $1 \mathrm{IU} / \mathrm{kg}$ injection of secretin, simultaneously with another $1 \mathrm{IU} / \mathrm{kg} 2$-minute infusion of secretin. In contrast, perfusion was measured only two minutes after the first secretin infusion (13). Since secretin stimulates BAT endogenously instead of through a faster neuronally mediated effect, the perfusion scan was likely conducted too early to measure secretin's effect on BAT perfusion.

Evidence of a catabolic effect was found with indirect calorimetry: whole body energy expenditure increased by secretin compared to placebo (13). BAT computer tomography radiodensity was increased at the end of the scan, compared to the start, and this increase was associated with whole body fat oxidation after secretin infusion (13). Higher adipose tissue radiodensity indicates reduced intracellular triglycerides or increased perfusion (106) and as such, the results could indicate that secretin induces BAT fatty acid oxidation.

In a subsequent study, we showed that secretin administration changed the brain's responses (as measured by the blood-oxygen- 
level-dependent signal by functional magnetic resonance imaging) to palatable vs non-palatable food cues (13). In the placebo condition, visual exposure to palatable versus non-palatable foods increased hemodynamic brain activity in the medial frontal cortex, cingulate cortex, caudate and middle and posterior insula, while this anticipatory reward-sensitive coding of the food images was abolished after secretin infusion (13). Satiety was assessed with the composite satiety score using visual analogue scale questions. We found that secretin increased the subjective satiety compared to placebo in fasting conditions and during early feeding, but this effect was no longer significant in the postprandial evaluation (13). Since subjects were instructed to feed until satiated, postprandial differences in satiety were not expected. Meal consumption following secretin was not statistically significantly decreased compared to placebo, but our study was underpowered to explore this endpoint. However, secretin delayed resumption to eat after the test meal, with a mean delay of 39 minutes, as compared to placebo (13).

All in all, our results indicate that the gut - BAT - brain axis previously shown in mice, translates to healthy, normal weight humans (Figure 2). Secretin activates BAT and increases whole body energy expenditure in humans, making it a catabolic agent. It also has an attenuating effect on anticipatory reward responses to appetizing food, increases satiation pre-prandially and in early feeding and delays resumption to eat. These results highlight that secretin has a rare dual role on energy homeostasis in humans, potentially both increasing energy expenditure and decreasing energy intake.

\section{CONCLUSIONS AND FUTURE DIRECTIONS}

Despite enormous efforts from several metabolic units around the globe, a complete and long-lasting resolution of obesity relies predominantly on bariatric surgery. However, BS is an invasive procedure, which is not widely and equally available around the globe. Many patients do not represent good candidates for undergoing BS and some do not wish to undergo BS. Also, even though the safety of BS has been proven, some "bariatric" patients may suffer from post-prandial hypoglycaemia (mild, moderate, or severe) (107), nutritional deficits, or gastrointestinal occlusions that need emergency treatment. Thus, identifying pathways that lead to obesity (appetite dysregulation, or decreased thermogenesis) for medical treatments of obesity is taking on a new urgency.

\section{REFERENCES}

1. Bessesen DH, Van Gaal LF. Progress and Challenges in Anti-Obesity Pharmacotherapy. Lancet Diabetes Endocrinol (2018) 6:237-48. doi: 10.1016/S2213-8587(17)30236-X

2. Mokdad AH, Ford ES, Bowman BA, Dietz WH, Vinicor F, Bales VS, et al. Prevalence of Obesity, Diabetes, and Obesity-Related Health Risk Factors, 2001. JAMA (2003) 289:76-9. doi: 10.1001/jama.289.1.76

3. Ho AJ, Raji CA, Becker JT, Lopez OL, Kuller LH, Hua X, et al. Obesity Is Linked With Lower Brain Volume in $700 \mathrm{AD}$ and MCI Patients. Neurobiol Aging (2010) 31:1326-39. doi: 10.1016/j.neurobiolaging.2010.04.006
In this review we have highlighted secretin's pleiotropic and somewhat forgotten metabolic roles. Most importantly, our recent findings show that secretin both increases energy expenditure and reduces appetite, making it a potential anti-obesity agent. The problem with only aiming to increase energy expenditure as a weight loss treatment is that increased energy expenditure leads to increased energy intake (108). Secretin's dual effect on energy homeostasis makes it a very attractive candidate for future studies. Still, much work is warranted to investigate the potential of secretin as a weight-reducing agent. Our volunteers were all healthy, normal weight and male. Whether this gut-BAT-brain axis is preserved in overweight and obese individuals needs to be demonstrated. In our study, we infused intravenously a synthetic human secretin with a rapid half-life. Currently, there is no long-acting secretin analogue for human use, but it would be warranted to investigate whether a longer acting secretin analogue could provide similar or even more pronounced effects. The serum secretin levels measured in our study after intravenous infusions were similar to postprandial secretin levels. Supra-physiological levels of secretin could have a more pronounced effect on appetite and energy expenditure. Furthermore, larger clinical trials are needed in order to confirm pre-prandially administered secretin's potential in reducing energy intake in humans. All in all, further clinical trials on secretin are warranted, as it seems to have a dual effect on energy homeostasis and could have potential in weight control.

\section{AUTHOR CONTRIBUTIONS}

SL, ER, and M-JH drafted the manuscript. PN critically revised the text. All authors contributed to the article and approved the submitted version.

\section{FUNDING}

The study was conducted within the Centre of Excellence into Cardiovascular and Metabolic Diseases supported by the Academy of Finland (grant no. 307402), University of Turku, Åbo Akademi University; and funded by the Instrumentarium Science Foundation (grant no. 190014) (SL), The Paulo Foundation (SL), Turku University Hospital Foundation (SL) and The Finnish Medical Foundation (grant no. 2985) (SL).

4. Rebelos E, Moriconi D, Virdis A, Taddei S, Foschi D, Nannipieri M. Letter to the Editor: Importance of Metabolic Health in the Era of COVID-19. Metabolism (2020) 108:154247. doi: 10.1016/j.metabol.2020.154247

5. Moriconi D, Masi S, Rebelos E, Virdis A, Manca ML, De Marco S, et al. Obesity Prolongs the Hospital Stay in Patients Affected by COVID-19, and may Impact on SARS-COV-2 Shedding. Obes Res Clin Pract (2020) 14:2059. doi: 10.1016/j.orcp.2020.05.009

6. Yang J, Ma Z, Lei Y. A Meta-Analysis of the Association Between Obesity and COVID-19. Epidemiol Infect (2020) 149:e11. doi: 10.1017/S0950268820003027

7. Global Burden of Cardiovascular Diseases Collaboration, Roth GA, Johnson CO, Abate KH, Abd-Allah F, Ahmed M, et al. The Burden of Cardiovascular 
Diseases Among US States, 1990-2016. JAMA Cardiol (2018) 3:375-89. doi: 10.1001/jamacardio.2018.0385

8. Yoshino M, Kayser BD, Yoshino J, Stein RI, Reeds D, Eagon JC, et al. Effects of Diet Versus Gastric Bypass on Metabolic Function in Diabetes. N Engl J Med (2020) 383:721-32. doi: 10.1056/NEJMoa2003697

9. Wilding JPH, Batterham RL, Calanna S, Davies M, Van Gaal LF, Lingvay I, et al. Once-Weekly Semaglutide in Adults With Overweight or Obesity. N Engl J Med (2021) 384:989. doi: 10.1056/NEJMoa2032183

10. Afroze S, Meng F, Jensen K, McDaniel K, Rahal K, Onori P, et al. The Physiological Roles of Secretin and its Receptor. Ann Trans Med (2013) 1 (3):29. doi: 10.3978/J.ISSN.2305-5839.2012.12.01

11. Mason JC, Murphy RF, Henry RW, Buchanan KD. Starvation-Induced Changes in Secretin-Like Immunoreactivity of Human Plasma. Biochim Biophys Acta (1979) 582:322-31. doi: 10.1016/0304-4165(79)90394-5

12. Li Y, Schnabl K, Gabler SM, Willershäuser M, Reber J, Karlas A, et al. Secretin-Activated Brown Fat Mediates Prandial Thermogenesis to Induce Satiation. Cell (2018) 175:1561-1574.e12. doi: 10.1016/j.cell. 2018.10.016

13. Laurila S, Sun L, Lahesmaa M, Schnabl K, Laitinen K, Klén R, et al. Secretin Activates Brown Fat and Induces Satiation. Nat Metab (2021) 3:798-809. doi: 10.1038/s42255-021-00409-4

14. Modvig IM, Andersen DB, Grunddal KV, Kuhre RE, Martinussen C, Christiansen CB, et al. Secretin Release After Roux-En-Y Gastric Bypass Reveals a Population of Glucose-Sensitive S Cells in Distal Small Intestine. Int J Obes (2020) 44:1859-71. doi: 10.1038/s41366-020-0541-7

15. Bateman A, Martin MJ, Orchard S, Magrane M, Agivetova R, Ahmad S, et al. UniProt: The Universal Protein Knowledgebase in 2021. Nucleic Acids Res (2021) 49:D480-9. doi: 10.1093/nar/gkaal100

16. Häcki WH. Secretin. Clin Gastroenterol (1980) 9:609-32. doi: 10.1016/ S0300-5089(21)00474-0

17. Uhlén M, Fagerberg L, Hallström BM, Lindskog C, Oksvold P, Mardinoglu A, et al. Tissue-Based Map of the Human Proteome. Science (2015) 347 (6220):1260419. doi: 10.1126/science.1260419

18. Chey WY, Lee YH, Hendricks JG, Rhodes RA, Tai HH. Plasma Secretin Concentrations in Fasting and Postprandial State in Man. Am J Digestive Dis (1978) 23:981-8. doi: 10.1007/BF01263096

19. Fahrenkrug J, de Muckadell OBS. Plasma Secretin Concentration in Man: Effect of Intraduodenal Glucose, Fat, Amino Acids, Ethanol, HCI, or Ingestion of a Meal. Eur J Clin Invest (1977) 7:201-3. doi: 10.1111/j.13652362.1977.tb01598.x

20. Green GM, Taguchi S, Friestman J, Chey WY, Liddle RA. Plasma Secretin, CCK, and Pancreatic Secretion in Response to Dietary Fat in the Rat. Am J Physiol (1989) 256:G1016-1021. doi: 10.1152/ajpgi.1989.256.6.G1016

21. Yago MD, Serrano P, Mañas M, Mataix J, Medrano J, Calpena R, et al. Release of Secretin and Somatostatin After Test Meals With Different FattyAcid Composition in Cholecystectomized Humans. J Nutr Biochem (1998) 9:186-92. doi: 10.1016/S0955-2863(97)00180-0

22. Li P, Song Y, Lee KY, Chang TM, Chey WY. A Secretin Releasing Peptide Exists in Dog Pancreatic Juice. Life Sci (2000) 66:1307-16. doi: 10.1016/ S0024-3205(00)00438-0

23. Li P, Lee KY, Chang TM, Chey WY. Mechanism of Acid-Induced Release of Secretin in Rats: Presence of a Secretin-Releasing Peptide. J Clin Invest (1990) 86:1474-9. doi: 10.1172/JCI114864

24. Li JP, Chang TM, Wagner D, Chey WY. Pancreatic Phospholipase A2 From the Small Intestine Is a Secretin-Releasing Factor in Rats. Am J Physiol Gastrointestinal Liver Physiol (2001) 281(2):G526-32. doi: 10.1152/ajpgi.2001. 281.2.g526

25. Chang TM, Chang CH, Wagner DR, Chey WY. Porcine Pancreatic Phospholipase A2 Stimulates Secretin Release From Secretin-Producing Cells. J Biol Chem (1999) 274:10758-64. doi: 10.1074/jbc.274.16.10758

26. Moore BA, Morris GP, Vanner S. A Novel In Vitro Model of Brunner's Gland Secretion in the Guinea Pig Duodenum. Am J Physiol Gastrointest Liver Physiol (2000) 278:G477-485. doi: 10.1152/ajpgi.2000.278.3.G477

27. Kirkegaard P, Skov Olsen P, Seier Poulsen S, Holst JJ, Schaffalitzky de Muckadell OB, Christiansen J. Effect of Secretin and Glucagon on Brunner's Gland Secretion in the Rat. Gut (1984) 25:264-8. doi: 10.1136/ gut.25.3.264
28. Chey WY, Chang T-M. Secretin: Historical Perspective and Current Status. Pancreas (2014) 43:162-82. doi: 10.1097/01.mpa.0000437325.29728.d6

29. Pissidis AG, Bomback CT, Merchant F, Nyhus LM. Hormonal Regulation of Bile Secretion: A Study in the Isolated, Perfused Liver. Surgery (1969) 66 (6):1075-84.

30. Hirose S, Shimazaki K, Hattori N. Effect of Secretin and Caerulein on the Absorption of Water, Electrolytes and Glucose From the Jejunum of Dogs. Digestion (1986) 35:205-10. doi: 10.1159/000199369

31. Pansu D, Bosshard A, Dechelette MA, Vagne M. Effect of Pentagastrin, Secretin and Cholecystokinin on Intestinal Water and Sodium Absorption in the Rat. Digestion (1980) 20:201-6. doi: 10.1159/000198440

32. Moritz M, Finkelstein G, Meshkinpour H, Fingerut J, Lorber SH. Effect of Secretin and Cholecystokinin on the Transport of Electrolyte and Water in Human Jejunum. Gastroenterology (1973) 64:76-80. doi: 10.1016/S00165085(73)80093-9

33. Dollinger HC, Raptis S, Rommel K, Pfeiffer EF. Effects of Secretin and Cholecystokinin-Pancreocymin on Water, Electrolyte and Glucose Absorption in Human Jejunum. A Comparison Between Different Hormone Preparations. Res Exp Med (Berl) (1982) 180:215-21. doi: 10.1007/BF01852293

34. Beglinger C, Gyr K, Werth B, Keller U, Girard J. Comparative Effects of Synthetic and Natural Secretin on Pancreatic Secretion and on Secretin, Insulin, and Glucagon Levels in Man. Digestive Dis Sci (1982) 27:231-3. doi: $10.1007 / \mathrm{BF} 01296921$

35. Christ A, Werth B, Hildebrand P, Gyr K, Stalder GA, Beglinger C. Human Secretin. Biologic Effects and Plasma Kinetics in Humans. Gastroenterology (1988) 94:311-6. doi: 10.1016/0016-5085(88)90417-9

36. Schaffalitzky de Muckadell OB, Fahrenkrug J, Watt-Boolsen S, Worning H. Pancreatic Response and Plasma Secretin Concentration During Infusion of Low Dose Secretin in Man. Scandinavian J Gastroenterol (1978) 13:305-11. doi: $10.3109 / 00365527809179825$

37. Kolts BE, McGuigan JE. Radioimmunoassay Measurement of Secretin HalfLife in Man. Gastroenterology (1977) 72:55-60. doi: 10.1016/S0016-5085(77) 80303-X

38. Curtis PJ, Fender HR, Rayford PL, Thompson JC. Catabolism of Secretin by the Liver and Kidney. Surgery (1976) 80(2):259-65.

39. Makawa S, Okumura K. Distribution and Metabolism of Secretin and Aprotinin in Isolated Perfused Rat Pancreas. J Pharmacobio-Dynamics (1982) 5:526-33. doi: 10.1248/bpb1978.5.526

40. Thompson JC, Llanos OL, Teichmann RK, Schafmayer A, Rayford PL. Catabolism of Gastrin and Secretin. World J Surg (1979) 3:469-75. doi: 10.1007/BF01556108

41. Curtis PJ, Fender HR, Rayford PL, Thompson JC. Disappearance Half Time of Endogenous and Exogenous Secretin in Dogs. Gut (1976) 17:595-9. doi: 10.1136/gut.17.8.595

42. Naruse S. Renal Handling of Secretin in Dogs: Free and Stop Flow Analyses. Metabolism: Clin Exp (1980) 29:1237-41. doi: 10.1016/00260495(80)90151-1

43. Curtis PJ, Miller TA, Rayford PL, Thompson JC. The Effect of Nephrectomy on the Catabolism of Secretin. Am J Surg (1977) 133:52-4. doi: 10.1016/ 0002-9610(77)90192-1

44. Metz DC. Diagnosis of the Zollinger-Ellison Syndrome. Clin Gastroenterol Hepatol (2012) 10:126-30. doi: 10.1016/j.cgh.2011.07.012

45. Johnson LR, Grossman MI. Effects of Fat, Secretin, and Cholecystokinin on Histamine-Stimulated Gastric Secretion. Am J Physiol (1969) 216:1176-9. doi: 10.1152/ajplegacy.1969.216.5.1176

46. Moolsintong P, Burton FR. Pancreatic Function Testing is Best Determined by the Extended Endoscopic Collection Technique. Pancreas (2008) 37:41821. doi: $10.1097 / \mathrm{mpa} .0 \mathrm{~b} 013 \mathrm{e} 31816 \mathrm{fd} 7 \mathrm{a} 4$

47. Dreiling DA. Pancreatic Secretory Testing in 1974. Gut (1975) 16:653-7. doi: 10.1136/gut.16.8.653

48. Chamokova B, Bastati N, Poetter-Lang S, Bican Y, Hodge JC, Schindl M, et al. The Clinical Value of Secretin-Enhanced MRCP in the Functional and Morphological Assessment of Pancreatic Diseases. Br J Radiol (2018) 91:20170677. doi: 10.1259/bjr.20170677

49. Waldum HL, Sundsfjord JA, Aanstad U, Burhol PG. The Effect of Secretin on Renal Haemodynamics in Man. Scand J Clin Lab Invest (1980) 40:475-8. doi: $10.3109 / 00365518009101870$ 
50. Gunnes P, Waldum HL, Rasmussen K, Ostensen H, Burhol PG. Cardiovascular Effects of Secretin Infusion in Man. Scand J Clin Lab Invest (1983) 43:637-42. doi: 10.3109/00365518309168843

51. Gunnes P, Rasmussen K. Haemodynamic Effects of Pharmacological Doses of Secretin in Patients With Impaired Left Ventricular Function. Eur Heart J (1986) 7:146-9. doi: 10.1093/oxfordjournals.eurheartj.a062037

52. Davis RJ, Page KJ, Dos Santos Cruz GJ, Harmer DW, Munday PW, Williams SJ, et al. Expression and Functions of the Duodenal Peptide Secretin and its Receptor in Human Lung. Am J Respir Cell Mol Biol (2004) 31:302-8. doi: $10.1165 / \mathrm{rcmb} .2004-0035 \mathrm{OC}$

53. Barkauskas CE, Cronce MJ, Rackley CR, Bowie EJ, Keene DR, Stripp BR, et al. Type 2 Alveolar Cells Are Stem Cells in Adult Lung. J Clin Invest (2013) 123:3025-36. doi: 10.1172/JCI68782

54. Mutt V, Carlquist M, Tatemoto K. Secretin-Like Bioactivity in Extracts of Porcine Brain. Life Sci (1979) 25:1703-7. doi: 10.1016/0024-3205(79)90472-7

55. Köves K, Kausz M, Reser D, Illyés G, Takács J, Heinzlmann A, et al. Secretin and Autism: A Basic Morphological Study About the Distribution of Secretin in the Nervous System. Regul Pept (2004) 123:209-16. doi: 10.1016/ j.regpep.2004.04.026

56. Ng SSM, Yung WH, Chow BKC. Secretin as a Neuropeptide. Mol Neurobiol (2002) 26:97-107. doi: 10.1385/MN:26:1:097

57. Jukkola PI, Rogers JT, Kaspar BK, Weeber EJ, Nishijima I. Secretin Deficiency Causes Impairment in Survival of Neural Progenitor Cells in Mice. Hum Mol Genet (2011) 20:1000-7. doi: 10.1093/hmg/ddq545

58. Yamagata T, Urano H, Weeber EJ, Nelson DL, Nishijima I. Impaired Hippocampal Synaptic Function in Secretin Deficient Mice. Neuroscience (2008) 154:1417-22. doi: 10.1016/j.neuroscience.2008.04.037

59. Schwarzschild MA, Zigmond RE. Secretin and Vasoactive Intestinal Peptide Activate Tyrosine Hydroxylase in Sympathetic Nerve Endings. J Neurosci (1989) 9:160-6. doi: 10.1523/JNEUROSCI.09-01-00160.1989

60. Propst F, Moroder L, Wünsch E, Hamprecht B. The Influence of Secretin, Glucagon and Other Peptides, of Amino Acids, Prostaglandin Endoperoxide Analogues and Diazepam on the Level of Adenosine 3',5'-Cyclic Monophosphate in Neuroblastoma X Glioma Hybrid Cells. J Neurochem (1979) 32:1495-500. doi: 10.1111/j.1471-4159.1979.tb11090.x

61. Ip NY, Baldwin C, Zigmond RE. Regulation of the Concentration of Adenosine 3',5'-Cyclic Monophosphate and the Activity of Tyrosine Hydroxylase in the Rat Superior Cervical Ganglion by Three Neuropeptides of the Secretin Family. J Neurosci (1985) 5:1947-54. doi: 10.1523/JNEUROSCI.05-07-01947.1985

62. Schwarzschild MA, Zigmond RE. Effects of Peptides of the SecretinGlucagon Family and Cyclic Nucleotides on Tyrosine Hydroxylase Activity in Sympathetic Nerve Endings. J Neurochem (1991) 56:400-6. doi: 10.1111/j.1471-4159.1991.tb08165.x

63. Babu GN, Vijayan E. Plasma Gonadotropin, Prolactin Levels and Hypothalamic Tyrosine Hydroxylase Activity Following Intraventricular Bombesin and Secretin in Ovariectomized Conscious Rats. Brain Res Bull (1983) 11:25-9. doi: 10.1016/0361-9230(83)90053-9

64. Chu JYS, Yung WH, Chow BKC. Secretin: A Pleiotrophic Hormone. Ann N Y Acad Sci (2006) 1070:27-50. doi: 10.1196/annals.1317.013

65. Yung WH, Leung PS, Ng SSM, Zhang J, Chan SCY, Chow BKC. Secretin Facilitates GABA Transmission in the Cerebellum. J Neurosci (2001) 21:7063-8. doi: 10.1523/jneurosci.21-18-07063.2001

66. Lee SMY, Chen L, Chow BKC, Yung WH. Endogenous Release and Multiple Actions of Secretin in the Rat Cerebellum. Neuroscience (2005) 134:377-86. doi: 10.1016/j.neuroscience.2005.04.009

67. Velmurugan S, Brunton PJ, Leng G, Russell JA. Circulating Secretin Activates Supraoptic Nucleus Oxytocin and Vasopressin Neurons via Noradrenergic Pathways in the Rat. Endocrinology (2010) 151:2681-8. doi: 10.1210/en.2009-1440

68. Chu JYS, Lee LTO, Lai CH, Vaudry H, Chan YS, Yung WH, et al. Secretin as a Neurohypophysial Factor Regulating Body Water Homeostasis. Proc Natl Acad Sci USA (2009) 106:15961-6. doi: 10.1073/pnas.0903695106

69. Chu JYS, Cheng CYY, Lee VHY, Chan YS, Chow BKC. Secretin and Body Fluid Homeostasis. Kidney Int (2011) 79:280-7. doi: 10.1038/ki.2010.397

70. Chu JYS, Cheng CYY, Sekar R, Chow BKC. Vagal Afferent Mediates the Anorectic Effect of Peripheral Secretin. PloS One (2013) 8:e64859. doi: 10.1371/journal.pone.0064859
71. Horvath K, Stefanatos G, Sokolski KN, Wachtel R, Nabors L, Tildon JT. Improved Social and Language Skills After Secretin Administration in Patients With Autistic Spectrum Disorders. J Assoc Acad Minority Physicians: Off Publ Assoc Acad Minority Physicians (1998) 9(1):9-15.

72. Sandler AD, Sutton KA, DeWeese J, Girardi MA, Sheppard V, Bodfish JW. Lack of Benefit of a Single Dose of Synthetic Human Secretin in the Treatment of Autism and Pervasive Developmental Disorder. N Engl J Med (1999) 341:1801-6. doi: 10.1056/NEJM199912093412404

73. Yang H, Wang L, Wu SV, Tay J, Goulet M, Boismenu R, et al. Peripheral Secretin-Induced Fos Expression in the Rat Brain is Largely Vagal Dependent. Neuroscience (2004) 128:131-41. doi: 10.1016/j.neuroscience. 2004.06.027

74. Banks WA, Goulet M, Rusche JR, Niehoff ML, Boismenu R. Differential Transport of a Secretin Analog Across the Blood-Brain and BloodCerebrospinal Fluid Barriers of the Mouse. J Pharmacol Exp Ther (2002) 302:1062-9. doi: 10.1124/JPET.102.036129

75. Barbezat GO, Isenberg JI, Grossman MI. Diuretic Action of Secretin in Dog. Proc Soc Exp Biol Med (1972) 139:211-5. doi: 10.3181/00379727-139-36111

76. Charlton CG, Quirion R, Handelmann GE, Miller RL, Jensen RT, Finkel MS, et al. Secretin Receptors in the Rat Kidney: Adenylate Cyclase Activation and Renal Effects. Peptides (1986) 7:865-71. doi: 10.1016/0196-9781(86)90107-5

77. Lameire N, Vanholder R, Ringoir S, Leusen I. Role of Medullary Hemodynamics in the Natriuresis of Drug-Induced Renal Vasodilation in the Rat. Circ Res (1980) 47:839-44. doi: 10.1161/01.res.47.6.839

78. Marchand GR. Effect of Secretin on Glomerular Dynamics in Dogs. Am J Physiol (1986) 250:F256-260. doi: 10.1152/ajprenal.1986.250.2.F256

79. Chu JYS, Chung SCK, Lam AKM, Tam S, Chung SK, Chow BKC. Phenotypes Developed in Secretin Receptor-Null Mice Indicated a Role for Secretin in Regulating Renal Water Reabsorption. Mol Cell Biol (2007) 27:2499-511. doi: 10.1128/mcb.01088-06

80. Cheng CYY, Chu JYS, Chow BKC. Central and Peripheral Administration of Secretin Inhibits Food Intake in Mice Through the Activation of the Melanocortin System. Neuropsychopharmacol (2011) 36:459-71. doi: $10.1038 /$ npp.2010.178

81. Lerner RL, Porte D. Studies of Secretin-Stimulated Insulin Responses in Man. J Clin Invest (1972) 51:2205-10. doi: 10.1172/JCI107028

82. Lerner RL, Porte D. Uniphasic Insulin Responses to Secretin Stimulation in Man. J Clin Invest (1970) 49:2276-80. doi: 10.1172/JCI106447

83. Fahrenkrug J, Schaffalitzky de Muckadell OB, Kühl C. Effect of Secretin on Basal- and Glucose-Stimulated Insulin Secretion in Man. Diabetologia (1978) 14:229-34. doi: 10.1007/BF01219421

84. Halter JB, Porte D. Mechanisms of Impaired Acute Insulin Release in Adult Onset Diabetes: Studies With Isoproterenol and Secretin. J Clin Endocrinol Metab (1978) 46:952-60. doi: 10.1210/jcem-46-6-952

85. Sekar R, Chow BKC. Lipolytic Actions of Secretin in Mouse Adipocytes. J Lipid Res (2014) 55:190-200. doi: 10.1194/jlr.M038042

86. Butcher RW, Carlson LA. Effects of Secretin on Fat Mobilizing Lipolysis and Cyclic AMP Levels in Rat Adipose Tissue. Acta Physiologica Scandinavica (1970) 79:559-63. doi: 10.1111/j.1748-1716.1970.tb04758.x

87. Braun K, Oeckl J, Westermeier J, Li Y, Klingenspor M. Non-Adrenergic Control of Lipolysis and Thermogenesis in Adipose Tissues. J Exp Biol (2018) 221:jeb165381. doi: 10.1242/jeb.165381

88. Bell PM, Henry RW, Buchanan KD, Alberti KGMM. Cimetidine Fails to Suppress the Rise in Plasma Secretin During Fasting. Regul Peptides (1985) 10:127-31. doi: 10.1016/0167-0115(85)90007-2

89. Manabe T, Tanaka Y, Yamaki K, Asano N, Nonaka A, Hirano T, et al. The Role of Plasma Secretin During Starvation in Dogs. Gastroenterol Jpn (1987) 22:756-8. doi: 10.1007/BF02776750

90. Stout RW, Henry RW, Buchanan KD. Triglyceride Metabolism in Acute Starvation: The Role of Secretin and Glucagon. Eur J Clin Invest (1976) 6:179-85. doi: 10.1111/j.1365-2362.1976.tb00509.x

91. Thuesen B, de Muckadell OBS, Holst JJ, Bahnsen M. The Relationship of Secretin and Somatostatin Levels in Plasma to Glucose Administration and Acid Secretion During Fasting. Am J Gastroenterol (1987) 82:723-6. doi: 10.1111/j.1572-0241.1987.tb01772.x

92. Hilsted J, Galbo H, Sonne B, Schwartz T, Fahrenkrug J, de Muckadell OB, et al. Gastroenteropancreatic Hormonal Changes During Exercise. Am J Physiol (1980) 239:G136-140. doi: 10.1152/ajpgi.1980.239.3.G136 
93. O’Connor AM, Johnston CF, Buchanan KD, Boreham C, Trinick TR, Riddoch CJ. Circulating Gastrointestinal Hormone Changes in Marathon Running. Int J Sports Med (1995) 16:283-7. doi: 10.1055/s-2007-973006

94. Andrews WJ, Henry RW, Alberti KGMM, Buchanan KD. The GastroEntero-Pancreatic Hormone Response to Fasting in Obesity. Diabetologia (1981) 21:440-5. doi: 10.1007/BF00257783

95. Vezina WC, Paradis RL, Grace DM, Zimmer RA, Lamont DD, Rycroft KM, et al. Increased Volume and Decreased Emptying of the Gallbladder in Large (Morbidly Obese, Tall Normal, and Muscular Normal) People. Gastroenterology (1990) 98:1000-7. doi: 10.1016/0016-5085(90)90025-V

96. Miegueu P, Cianflone K, Richard D, St-Pierre DH. Effect of Secretin on Preadipocyte, Differentiating and Mature Adipocyte Functions. Int J Obes (2013) 37:366-74. doi: 10.1038/ijo.2012.73

97. Miskowiak J, Andersen B, Stadil F, Schaffalitzky de Muckadell OB. Plasma Secretin Before and After Gastroplasty for Morbid Obesity. Scand J Clin Lab Invest (1984) 44:363-5. doi: 10.3109/00365518409083821

98. Nergård BJ, Lindqvist A, Gislason HG, Groop L, Ekelund M, Wierup N, et al. Mucosal Glucagon-Like Peptide-1 and Glucose-Dependent Insulinotropic Polypeptide Cell Numbers in the Super-Obese Human Foregut After Gastric Bypass. Surg Obes Relat Dis (2015) 11:1237-46. doi: 10.1016/j.soard.2015.03.021

99. Zhang C, Rigbolt K, Petersen SL, Biehl Rudkjær LC, Schwahn U, FernandezCachon ML, et al. The Preprohormone Expression Profile of Enteroendocrine Cells Following Roux-En-Y Gastric Bypass in Rats. Peptides (2019) 118:170100. doi: 10.1016/j.peptides.2019.170100

100. Rhee NA, Wahlgren CD, Pedersen J, Mortensen B, Langholz E, Wandall EP, et al. Effect of Roux-En-Y Gastric Bypass on the Distribution and Hormone Expression of Small-Intestinal Enteroendocrine Cells in Obese Patients With Type 2 Diabetes. Diabetologia (2015) 58:2254-8. doi: 10.1007/s00125-015-3696-3

101. Rebelos E, Dadson P, Oikonen V, Iida H, Hannukainen JC, Iozzo P, et al. Renal Hemodynamics and Fatty Acid Uptake: Effects of Obesity and Weight Loss. Am J Physiol Endocrinol Metab (2019) 317:E871-8. doi: 10.1152/ ajpendo.00135.2019

102. Rebelos E, Hirvonen J, Bucci M, Pekkarinen L, Nyman M, Hannukainen JC, et al. Brain Free Fatty Acid Uptake is Elevated in Morbid Obesity, and is Irreversible 6 Months After Bariatric Surgery: A Positron Emission Tomography Study. Diabetes Obes Metab (2020) 22:1074-82. doi: 10.1111/dom.13996

103. Oldgren J, Laurila S, Åkerblom A, Latva-Rasku A, Rebelos E, Isackson H, et al. Effects of 6 Weeks of Treatment With Dapagliflozin, a Sodium-Glucose Co-Transporter-2 Inhibitor, on Myocardial Function and Metabolism in
Patients With Type 2 Diabetes: A Randomized, Placebo-Controlled, Exploratory Study. Diabetes Obes Metab (2021) 23:1505-17. doi: 10.1111/ dom.14363

104. Honka M-J, Latva-Rasku A, Bucci M, Virtanen KA, Hannukainen JC, Kalliokoski KK, et al. Insulin-Stimulated Glucose Uptake in Skeletal Muscle, Adipose Tissue and Liver: A Positron Emission Tomography Study. Eur J Endocrinol (2018) 178:523-31. doi: 10.1530/EJE-17-0882

105. Carpentier AC, Blondin DP, Virtanen KA, Richard D, Haman F, Turcotte ÉE. Brown Adipose Tissue Energy Metabolism in Humans. Front Endocrinol (Lausanne) (2018) 9:447. doi: 10.3389/fendo.2018.00447

106. Din MU, Raiko J, Saari T, Saunavaara V, Kudomi N, Solin O, et al. Human Brown Fat Radiodensity Indicates Underlying Tissue Composition and Systemic Metabolic Health. J Clin Endocrinol Metab (2017) 102:2258-67. doi: 10.1210/jc.2016-2698

107. Rebelos E, Moriconi D, Scalese M, Denoth F, Molinaro S, Siciliano V, et al. Impact of Postprandial Hypoglycemia on Weight Loss After Bariatric Surgery. Obes Surg (2020) 30:2266-73. doi: 10.1007/s11695-020-04465-9

108. Polidori D, Sanghvi A, Seeley RJ, Hall KD. How Strongly Does Appetite Counter Weight Loss? Quantification of the Feedback Control of Human Energy Intake. Obes (Silver Spring) (2016) 24:2289-95. doi: 10.1002/ oby. 21653

Conflict of Interest: The authors declare that the research was conducted in the absence of any commercial or financial relationships that could be construed as a potential conflict of interest.

Publisher's Note: All claims expressed in this article are solely those of the authors and do not necessarily represent those of their affiliated organizations, or those of the publisher, the editors and the reviewers. Any product that may be evaluated in this article, or claim that may be made by its manufacturer, is not guaranteed or endorsed by the publisher.

Copyright (C) 2021 Laurila, Rebelos, Honka and Nuutila. This is an open-access article distributed under the terms of the Creative Commons Attribution License (CC BY). The use, distribution or reproduction in other forums is permitted, provided the original author(s) and the copyright owner(s) are credited and that the original publication in this journal is cited, in accordance with accepted academic practice. No use, distribution or reproduction is permitted which does not comply with these terms. 